\title{
UMA PERSPECTIVA PSICANALÍTICA SOBRE AS DEPRESSÕES NA ATUALIDADE
}

\author{
Érico Bruno Viana Campos \\ Universidade Estadual Paulista "Júlio de Mesquita Filho" (UNESP) - Campus de Bauru
}

\begin{abstract}
Resumo
O artigo pretende analisar o fenômeno da epidemia de depressão na atualidade como sintoma da configuração sócio-cultural da subjetividade contemporânea, por meio de uma crítica ao referencial da psicopatologia psiquiátrica a partir da psicanálise. Mostra a relevância de se tomar a depressão como expressão de um conluio na retirada do sujeito na contemporaneidade, fruto de um movimento de medicalização do social. Apresenta também um panorama da compreensão da depressão na psicopatologia psicanalítica, ressaltando sua inespecificidade estrutural e pontuando diferentes nuances acerca de seu posicionamento fundamental nas tradições lacaniana e das relações de objeto. Defende que se tome a problemática depressiva, em seus diferentes arranjos estruturais, como expressão de falhas ao longo do eixo narcísicomelancólico de constituição da subjetividade como um modelo pertinente e sistematizador para compreensão da problemática das depressões em psicanálise.

Palavras-chave: Depressão; Psicanálise; Psicopatologia; Medicalização; Cultura.
\end{abstract}

\section{A PSYCHOANALYTICAL PERSPECTIVE ON NOWADAYS DEPRESSION}

\begin{abstract}
The paper analyzes the phenomenon of epidemic depression nowadays as a symptom of the socio-cultural setting of contemporary subjectivity, through a critique to the framework of psychiatric psychopathology from psychoanalysis. It shows the importance of taking depression as an expression of collusion in the removal of the subject in contemporary times, as the result of a movement of social medicalization. It also presents an overview of the understanding of depression in psychoanalytic psychopathology, highlighting its structural unspecificity and pointing out different trends about their fundamental position in the Lacanian and object relations traditions. It argues that the depressive problems must be taken in their different structural arrangements, as an expression of failure and fixings along the narcissistic-melancholy axis of subjectivity constitution as a relevant and comprising model for understanding the problem of depression in psychoanalysis.
\end{abstract}

Keywords: Depression; Psychoanalysis; Psychopathology; Medicalization; Culture.

\section{UNA PERSPECTIVA PSICOANALÍTICA SOBRE LA DEPRESIÓN EN EL PRESENTE}

\begin{abstract}
Resumen
El artículo analiza el fenómeno de la epidemia de depresión hoy en día como un síntoma de la configuración sociocultural de la subjetividad contemporánea, a través de una crítica del marco de la psicopatología psiquiátrica desde el psicoanálisis. Esto demuestra la importancia de tomar la depresión como una expresión de la colusión en la eliminación de la materia en la época contemporánea, el resultado de un movimiento de medicalización social. También se presenta una visión general de la comprensión de la depresión en la psicopatología psicoanalítica, destacando su especificidad estructural y anotando diferentes matices sobre su posición fundamental en las tradiciones lacaniana y de las relaciones de objeto. Sostiene que tomamos los problemas depresivos en sus diferentes disposiciones estructurales, como una expresión de la falta a lo largo de la constitución narcisista-melancólica de la subjetividad como un modelo relevante y sistematico para la comprensión del problema de la depresión en el psicoanálisis.
\end{abstract}

Palabras clave: Depresión; Psicoanálisis; Psicopatología; Medicalización; Cultura. 


\section{INTRODUÇÃO}

A depressão se tornou um fenômeno significativo na configuração das psicopatologias contemporâneas, ganhando destaque não apenas no âmbito do discurso especializado das ciências, mas, também, marcando presença na linguagem do senso comum. Estar deprimido é praticamente uma condição do sujeito pós-moderno (Bauman, 1998), de tal forma que vivemos hoje sob o signo de uma verdadeira epidemia de depressão (Peres, 2003; Pignarre, 2012). A Organização Mundial de Saúde (2001) deflagrou o alerta de que a depressão alcançou índices epidemiológicos alarmantes, a tal ponto de ser uma das patologias que mais causa perdas econômicas no mundo, ao lado do câncer, de doenças cardíacas e de doenças infecto-contagiosas como a AIDS, tuberculose etc. Outro dado significativo é que os maiores prescritores de drogas antidepressivas no mundo são clínicos gerais, ginecologistas, dermatologistas, neurologistas e psiquiatras. (Wakefield \& Horwitz, 2010; Bogochovol, 2001). As posições se alternam, mas os psiquiatras não detêm mais a exclusividade do diagnóstico e da terapêutica.

Em função desse estado de coisas, cada vez mais, em vez de dor e sofrimento, se utiliza o termo depressão. Esse deslocamento de sentido não é ingênuo. Deve-se suspeitar desse suposto efeito inócuo das palavras. A psicanálise ensina o quanto à linguagem tem um papel fundamental na constituição do sujeito e, principalmente, como uma interpretação bem colocada tem o poder de gerar novos sentidos. O valor da linguagem na criação de significações não está naquilo que ela traz de certeza, mas no estranhamento que pode produzir no falante, ou seja, na possibilidade de abertura que ela traz para o seu desejo. Além disso, o uso das palavras remete ao contexto em que tais conceitos são produzidos. Assumir que essa vinculação é natural nada mais faz que obscurecer a história de produção desse conceito e, para ser um pouco mais radical, da própria configuração desse mal-estar.

Nesse sentido, pode-se pensar em um movimento ideológico responsável pela evidência que a depressão ganha entre as configurações do mal-estar na atualidade. Portanto, devemos suspeitar das certezas que nos aparecem como dadas e quando a palavra depressão aparece no discurso de alguém algo de um ocultamento do sofrimento psíquico pode estar aí em jogo. Para contribuir no encaminhamento dessa questão, o presente artigo pretende apresentar um olhar psicanalítico sobre a temática das depressões, focando em uma crítica da configuração contemporânea da sociedade que favorece a emergência da depressão como forma de adoecimento psíquico. Entende-se que a questão das depressões seja bastante significativa do mal-estar contemporâneo e também configure um exemplo importante da biologização e medicalização do discurso sobre o sofrimento psíquico que tem lugar na sociedade contemporânea. 


\section{A PSICOPATOLOGIA PSIQUIÁTRICA}

Fundamentalmente, a psicopatologia psiquiátrica afirma que a depressão é um transtorno de humor, segundo o Manual e Diagnóstico Estatístico de Transtornos Mentais (DSM; APA, 2002, 2014), ou um transtorno afetivo, segundo a Classificação Internacional de Doenças 10a edição (CID-10; OMS, 1993), caracterizado por um determinado quadro sintomatológico, em que estão presentes tanto sintomas psíquicos quanto corporais. São eles: humor deprimido e/ou maníaco, pensamentos negativos, culpa excessiva, ideação suicida, apatia, alterações no sono, alterações no apetite, agitação ou retardo psicomotor e fadiga.

O diagnóstico é dado em função do preenchimento de certo número desses requisitos, baseados em levantamentos estatísticos e epidemiológicos. Esses critérios são descritivos e objetivos, preterindo as nuances e peculiaridades subjetivas de uma avaliação clínica tradicional tanto em psiquiatria como em psicologia ou psicanálise (Rodrigues, 1999). Essa constelação de sintomas configura uma síndrome que, por sua vez, é remetida a um referencial explicativo de ordem neurofisiológica: trata-se de uma disfunção das vias seratoninérgicas e noradrenérgicas do sistema nervoso central. Daí a justificativa da terapia medicamentosa, que agiria diretamente na dimensão fisiológica do problema, uma vez que o fármaco aumenta a disponibilidade dos referidos neurotransmissores na fenda sináptica. O raciocínio fecha-se de forma cristalina: um diagnóstico rápido, fácil e universal, com uma terapêutica fundamentada em evidências científicas.

As classificações diagnósticas mais recentes são, portanto, o coroamento das exigências da chamada medicina baseada em evidências (Leite, 2002). Esse, contudo, é apenas o capítulo mais recente da eterna busca de um referencial teórico que norteie a psicopatologia psiquiátrica. Historicamente a psiquiatria teve dificuldades em se articular plenamente ao campo da medicina somática, uma vez que os preceitos da anátomo-patologia, que fundaram a medicina moderna, não puderam nortear o estudo das doenças mentais. Como mostrou Foucault (1978), a emergência da psiquiatria como um saber se deu atrelada a uma prática institucional e a um discurso moral. Portanto, o que se observa desde a constituição desse campo é a busca de um referencial explicativo para a psicopatologia. Passando inicialmente pela fenomenologia, esse problema ganhou certa estabilidade com a psicanálise - a teoria dinâmica em psiquiatria foi a base da psicopatologia psiquiátrica até a primeira metade do século $X X$. Contudo, a busca só veio se completar com a descoberta das drogas psicotrópicas e o desenvolvimento de uma compreensão neurofisiológica do funcionamento mental (Leite, 2002; Nogueira Filho, 2001).

A nosologia psiquiátrica clássica parte do pressuposto de que o diagnóstico é função de uma apreensão semiológica na qual os signos patognômicos são 
interpretados e articulados pelo médico em uma categorização que não é diretamente observável. Ou seja, a semiologia - o estudo dos sinais e sintomas fundamenta-se na possibilidade de abstração de alguns critérios que configuram uma síndrome (Dalgalarrondo, 2000). Já a etiologia da síndrome é buscada na referência ao funcionamento neurofisiológico. Aqui cabe a pergunta sobre o que veio primeiro: o psicofármaco ou a neurofisiologia. Essa pergunta pode parecer ingênua, mas traz uma questão importante, já que muitas das vezes o mecanismo neurofisiológico de uma determinada síndrome psicopatológica é inferida do mecanismo de ação do medicamento. Ou seja, é a ação do medicamento que circunscreve a patologia e não o contrário, como se poderia imaginar. Conforme afirma Caponi:

Como vemos é a partir da mediação do psicofármaco que os dois níveis de diagnóstico: o nível descritivo (DSM-IV) e o nível etiológico se articulam. O antidepressivo tem um efeito duplo: permite definir a etiologia (uma reação favorável ao Prozac (ISRS) indica déficit de serotonina) e permite otimizar e criar novos critérios diagnósticos (2009, p. 6-7)

São essas as questões que estão em jogo nas críticas que são feitas às classificações diagnósticas e ao furor medicamentoso; críticas que não vêm apenas de disciplinas como a psicologia e a psicanálise, mas de dentro do próprio campo da psiquiatria (Wakefield \& Horwitz, 2010; Kramer, 1994). Muitos psiquiatras, principalmente os europeus, herdeiros da tradição psicopatológica francesa e alemã, se mostraram contra a hegemonia dos critérios operacionais que levaram ao DSM-IV e acabaram por influenciar a parte de diagnóstico dos transtornos mentais da CID-10 (Peres, 2003). Essa concepção hegemônica teve origem na psiquiatria acadêmica americana, capitaneada pela chamada escola de Saint Louis (Leite, 2002).

Para uma parte da psicologia e para a psicanálise, contudo, esse referencial epistemológico naturalista e positivista, baseado em uma separação clara entre sujeito e objeto, não se sustenta. Por conta da primazia da estratégia da escuta em um método que é fundamentalmente clínico, entende-se que a intersubjetividade é o real produtor de sentido (Birman, 1991; Gorayeb, 2002). O problema em jogo nas caracterizações diagnósticas atuais é, justamente, ter aberto mão do lugar da subjetividade no diagnóstico como garantia de objetividade e universalidade. Essa posição abre mão de hipóteses etiológicas e coloca no lugar critérios sintomatológicos, afirmando-se como uma construção "a-teórica". Ora, há um caráter ideológico intrínseco a essa afirmação. Os conceitos nosográficos são categorias epistemológicas - na medida em que são critérios que buscam apreender e organizar a pluralidade dos dados da realidade gerando um saber - e, como tais, não podem ser pensadas como entidades independentes de seu observador, de seu instrumental e de sua doutrina (Caponi, 2009). 
Essa manobra cria a ilusão que o corpo descrito pela neurofisiologia ou pela sintomatologia é mais real e mais concreto do que aquilo que é a dimensão representacional e simbólica da vida psíquica. Isso leva à recusa da etiologia psicogênica das patologias mentais. No caso específico da depressão, o que se observa é que a seção nosográfica dos distúrbios afetivos veio se consolidar nas duas últimas décadas, simultaneamente à perda do critério etiológico. 0 interessante é que ao mesmo tempo em que as classificações diagnósticas foram consolidando o movimento de anulação da subjetividade e da etiologia psicogênica, as categorias dos distúrbios afetivos foram aumentando em importância.

Anteriormente, os sintomas associados às alterações de humor faziam parte de outras categorias psicopatológicas. O exemplo clássico é a psicose maníaco-depressiva, descrita por Kraeplin, como uma perturbação de natureza psicótica, marcada pela oscilação do humor depressivo e maníaco. Além disso, as diferentes categorias eram definidas pela hipótese etiológica e não pela sintomatologia. Assim, nas edições mais antigas do DSM e da CID, havia a diferenciação entre distúrbios endógenos/reativos, hereditários/psicogênicos, autônomos/reativos e primários/secundários, por exemplo. Atualmente as dicotomias que estruturavam as hipóteses etiológicas foram abolidas, em nome de uma suposta continuidade entre todas as manifestações clínicas. Com isso multiplicam-se as subdivisões dentro dos transtornos de humor/afetivos.

Dentro das subdivisões gerais (transtornos depressivos, bipolares e outros transtornos de humor), há entre 29 e 36 subdivisões específicas, sem falar nos outros quadros em que comparece o humor depressivo, tais como: transtornos fóbico-ansiosos, ansiedade generalizada, transtorno obsessivo-compulsivo, transtornos de adaptação e stress pós-traumático (Peres, 2003). Esse movimento apenas se consolidou com a quinta edição do DSM, em que o número de categorias e subcategorias aumentou consideravelmente. Observa-se também que as causas mais diretamente relacionadas a contingências da vida acabam ficando de fora da categoria dos transtornos afetivos/humor (Wakefield \& Horwitz, 2010).

Por fim, cabe perguntar que benefícios trouxeram tamanhas inflexões de pensamento e de conduta. A farmacoterapia da depressão não é das mais bemsucedidas. Os índices de melhora no tratamento são medianos (60 a 65\%) e a taxa de recaída é bastante elevada ( $50 \%$ após um ano). Além do mais, não há sinais de diminuição da incidência de depressão, pelo contrário, em muitos lugares houve até aumento das taxas de suicídio. Sobretudo, se observa um grande risco de uso indiscriminado da medição (Kramer, 1994; Wakefield \& Horwitz, 2010). 


\section{O CONTEXTO SÓCIO-CULTURAL DA ATUALIDADE}

Para se entender o que faz da depressão uma psicopatologia emblemática do mal-estar na atualidade, é preciso partir de outro nível de questionamento. Voltando-se agora para o olhar das ciências humanas sobre os arranjos sociais e psíquicos contemporâneos, pode-se entender que esse estado de coisas não é desprovido de sentido, uma vez que tanto o arroubo medicamentoso quanto o surto depressivo compartilham de uma mesma lógica de produção de subjetividade na atualidade.

Há toda uma polêmica, que não interessa ao escopo desta discussão, sobre se o momento contemporâneo configura, de fato, uma ruptura com o período moderno e, portanto, uma pós-modernidade ou nada mais que um desdobramento, aprofundamento e mesmo radicalização das próprias teses que fundamental a modernidade (Birman, 2006; Bauman, 1998). De qualquer forma, este momento histórico da atualidade diz respeito à crise e desilusão quanto às promessas iluministas e liberais da modernidade, centradas em um referencial antropocêntrico, racional e laico de compreensão do sujeito e de organização da sociedade. Esse fenômeno se expressa de forma muito variadas, em diferentes níveis da cultura e da sociedade, sendo tematizado também por diferentes perspectivas dentro das ciências humanas, filosofia, política e estética. Em geral, diz respeito a uma modificação da experiência e configuração da subjetividade, em função de uma ampliação das referências simbólicas e espaciais, trazendo uma pluralidade de parâmetros culturais, que não mais se organizam de forma a pautar ideais consistentes, persistentes e definitivos para pautar as referências éticas, políticas e estéticas, além de servir de parâmetro para a definição de uma identidade. Essa ampliação no âmbito do espaço e das referências simbólicas é acrescida de uma aceleração no âmbito da temporalidade, marcada pela fragilidade e fugacidade dos parâmetros pautados pela cultura, que se esvanecem e modificam rapidamente, mas cuja perenidade se torna ela própria um princípio e um ideal, de forma tal que a transformação constante para dar conta de um presente que nunca se esgota se torna imperiosa.

Por fim, essa lógica de constante atualização e transformação em relação ao que se apresenta imediatamente e logo se esvai ou se torna datado e ultrapassado, implica uma transformação em relação ao sentido do passado e do futuro, já que os ideais simbólicos que costumavam referenciar o planejamento em relação a um projeto futuro e se embasar no peso de uma tradição que se confirma historicamente se fragilizam. Tudo isso caracteriza essa ideia geral da falência do ideal de sujeito moderno e da perda de referências sociais e culturais consistentes para a produção de identidades, cujo efeito psíquico sobre as pessoas é a da ordem do desamparo e da insegurança e também do individualismo. Decorre daí uma posição de trocar a segurança do amparo social pela insegurança de prazeres transgressivos e lábeis, em que o desapego dos 
vínculos relacionais em uma vertiginosa e constante reinvenção de si se apresenta como imperativo de felicidade e realização (Bauman, 1998).

Esse individualismo desamparado de um sujeito "cidadão do mundo" e, por isso, mesmo, identificado com lugar nenhum, é o exemplo mais ilustrativo dessa configuração subjetiva. Nesse sentido, na pós-modernidade configura-se um modo de subjetivação bastante especial. Apoiado na já longa tradição de discussão sobre essa temática, Birman (2001), caracteriza as subjetividades contemporâneas como centradas em um vínculo intersubjetivo fundamentalmente narcísico, permeado por exigências estéticas e performáticas. Essa autora parte das considerações de Lasch (1983) sobre uma cultura do narcisismo como característica das sociedades capitalistas tardias, em especial a americana a partir do pós-guerra, cujos reflexos analisa em seu livro do final dos anos 70, em que a lógica do consumo que fundamenta as relações econômicas passa também a pautar as relações pessoais e os princípios éticos gerais, refletindo sobre as identidades dos sujeitos. $\mathrm{Na}$ cultura do narcisismo os indivíduos têm a tarefa de construir-se e manter-se a partir do que é produzido nas relações de consumo, definindo seu status a partir desse circuito de aquisição de bens materiais e culturais, gerando um imperioso hedonismo e individualismo, em que o outro aparece como aquele que pode confirmar a projeção de sua autoimagem, gerando uma catastrófica corrosão nos ideais políticos comuns e coletivos de produção do bem-estar social. Dessa análise, Birman (2001) extrai a noção de um individualismo exacerbado na atualidade, em que os sujeitos vivem um autocentramento excessivo que, contudo, está o tempo todo remetido ao olhar do outro e, portanto, tem uma característica exteriorizada, em oposição ao individualismo moderno, que tinha características interiorizadas, íntimas e reflexivas. É como se o indivíduo precisasse cada vez mais do reconhecimento do outro na diferenciação de sua identidade, por meio de dispositivos culturais cada vez mais próximos de performances e espetáculos.

Nesse segundo ponto, Birman (2001) se apoia na proposição de Debord (1997), de uma sociedade do espetáculo. Esse conceito aprofunda a análise marxista sobre o fetiche da mercadoria e seus desdobramentos na teoria crítica da sociedade, lançando-a para um contexto do capitalismo pós-industrial e das mudanças políticas e culturais que já se anunciava no final dos anos 1960, quando a obra foi originalmente escrita. Em especial, discute o impacto do consumo e da comunicação de massa sobre as relações sociais e a produção de ideologias, produzindo uma transformação crucial na configuração desses vínculos, que configura propriamente a noção de espetáculo como conjunto de relações sociais mediadas pelo imaginário das produções midiáticas. Assim, as imagens se tornam o próprio meio da relação social e a sociedade do espetáculo seria a forma mais perversa da sociedade capitalista, pois nela a dimensão ilusória do fetiche da mercadoria se tornaria ilusoriamente e sedutoramente desprendido de sua base material. Nesse sentido, o que aponta também é a 
valorização do consumo como organizador das relações econômicas e sociais, mas ressaltando o papel da imagem e dos meios de comunicação como modos de manutenção da alienação e da dominação social, porém ocorrendo agora de forma difusa, menos dicotomizada e diferenciada, de forma tal que âmbitos como produção e consumo, lazer e política, público e privado se mesclam. Dessa análise sobre a forma midiática e imaginária dos vínculos contemporâneos, Birman (2001) vem ressaltar e aprofundar também a sua dimensão performática, no sentido de que a produção do sujeito mediada fundamentalmente pelo âmbito da imagem que produz de si em uma performance mediada pelos meios de comunicação, demanda a projeção de uma imagem ideal como forma de reconhecimento que se torna imperativa da organização subjetiva. É nesse ponto que o culto à imagem e se liga à noção de uma cultura do narcisismo, o que pode ser ilustrado pelo fenômeno contemporâneo de um ideal big brother de relações e pela noção de uma celebridade instantânea, em que o artifício da estética parece ser a única porta de reconhecimento, mesmo que por meros e fugazes quinze minutos de fama.

Por sua vez, essa noção do outro atuar como um reflexo que possibilita a configuração de uma imagem do que eu seja, configurando também certa dimensão de alienação também foi tematizada pela psicanálise, porém pela perspectiva da dimensão desejante do sujeito. Nesse ponto, Birman (2001) se apoia propriamente na concepção psicanalítica de narcisismo. O conceito de narcisismo diz respeito ao investimento da libido no eu e consiste em um momento essencial na constituição do sujeito, já que é nele que se constitui a identidade do eu e a diferenciação dessa instância do aparelho psíquico por identificação com os objetos primários de desejo, configurando um passo no desenvolvimento psicossexual da libido e das relações de objeto (Freud, 1914/1996). Essa dinâmica estabelece um modo de relação com os objetos e de imagem de si que é mediada por representações que se colocam como ideais, fruto de processos de identificação e idealização. As dinâmicas narcísicas são constituintes da personalidade, mas também se configuram no nível dos vínculos sociais e dinâmicas grupais, uma vez que a identificação com um objeto no lugar de ideal de ego é elemento fundamental da constituição dos laços e identidades grupais, configurando o que Freud (1921/1996) definiu como o fenômeno do narcisismo das pequenas diferenças.

Lacan (1949/1998) resgata a problemática do narcisismo em psicanálise, propondo toma-lo como momento formador da função do eu, por meio da identificação do bebê com os significantes fornecidos pela função materna, dando-Ihe uma unidade imaginária. Desse modo, enfatiza a dimensão alteritária na constituição da subjetividade, por meio da ideia de que o eu se constitui por identificação com o outro, sujeito encarnado por meio do qual se expressa a dimensão simbólica estrutural da linguagem, denominada de Outro. Contudo, a compreensão lacaniana da dinâmica narcísica está calcada no registro do 
imaginário, ou seja, de significações que funcionam segundo a lógica das imagens mentais, que tem como característica principal a completude e a correspondência nos processos de representação. Nesse sentido, as identificações imaginárias criam um estado de correspondência e reflexividade entre o eu e o outro que produzem uma dialética alienante, na medida em que o eu está totalmente referido ao desejo do outro, mas também extremamente violenta, na medida em que qualquer diferença mínima é energicamente rechaçada ou retroage sobre o eu, fragmentando-o. Portanto, o narcisismo, tal como tematizado por certa tradição da psicanálise, é um operador conceitual importante para pensar o regime de ilusões imaginárias e de alienação do eu em relações em que a alteridade do outro tende a ser desconsiderado, que se revela um momento constitutivo da subjetividade, mas também uma tônica no laço social contemporâneo.

Por esse caminho, Birman (2001, 2006) acrescenta um olhar psicanalítico à discussão sociológica precedente, trazendo aportes significativos para a compreensão da subjetividade contemporânea, propondo especificamente a noção de um ideal performático e estético como regulador preponderante do modo de subjetivação na atualidade. Dentro dessa perspectiva, é preciso entender que o narcisismo não pode ser entendido como egoísmo ou individualismo, no sentido de um auto-investimento de si que desconsidera os outros. O indivíduo contemporâneo é autocentrado, mas a referência ao outro é fundamental, contudo a relação com esse outro é narcísica. Sem isso, não se pode entender a urgência de reconhecimento efêmero que move a subjetividade na atualidade. Isso leva ao ponto ressaltado pelo autor, de uma verdadeira estetização da existência e de um imperativo performático cujo resultado e uma inflação do eu marcada pela imagem, pelo imediatismo e pelo consumismo, de forma tal que é a aparência o diferencial da identidade e o corpo o veículo preferencial de expressão e suporte da subjetividade.

Essa configuração do modo de subjetivação na atualidade incide sobremaneira nas formas de constituição e expressão do mal-estar e dos sintomas, modulando o que se convencionou chamar de psicopatologias contemporâneas, onde a depressão ganha destaque não só por sua prevalência epidemiológica, mas também por seu lugar paradigmático nesse contexto. Isso porque na atualidade nada é mais patológico do um distúrbio em que a o apelo estético, consumista e performático estejam ameaçados e a depressão, com seu embotamento afetivo e desejante, por meio de uma aversão ao contato e à visibilidade, com um desinvestimento do eu e do corpo, é justamente a expressão mais ilustrativa disto. A depressão, portanto, é um dos avessos desse ideal contemporâneo, assim como a histeria era o avesso da sociedade repressora do final do século XIX. Hoje em dia viver a sexualidade não é mais pecado; pecado é ficar deprimido. O psiquismo passa a ser regulado por um princípio, literalmente econômico, não sendo por acaso que as depressões 
psíquicas tendam a assumir configurações cíclicas, tal como a dinâmica da sociedade capitalista.

Dentro dessa configuração, não é de se estranhar que os remédios ganhem o estigma de recurso terapêutico plenamente efetivo. Foi inclusive em relação ao fenômeno da depressão que os avanços da psicofarmacologia se mostraram mais esperançosos e também mais ideológicos, quando do lançamento da fluoxetina como nova categoria de drogas antidepressivas nos anos 1990, quando o Prozac foi alardeado pela mídia como "pílula da felicidade" (Kramer, 1994). Desde então, o lugar da medicação nos tratamentos de saúde só veio aumentar, com o efeito de passar a se configurar de forma mais vertiginosa e ampla a concepção de uma medicalização do social. O conceito de medicalização foi cunhado e trabalhado em uma dimensão conceitual e histórica mais ampla por Foucault $(1998,2008)$, para afirmar o lugar de centralidade que passa a ocupar o saber médico a partir da modernidade na configuração da dinâmica social e política, sendo percussor do que denomina ao longo de sua obra de biopolítica. Contudo, mais recentemente foi problematizada por alguns autores como uma problemática emergente no campo da saúde (Ilich, 1975; Conrad, 2007), podendo ser basicamente definida como um processo pelo qual problemas não médicos passam a ser definidos e tratados como tais, ou seja, em que as diversas dimensões sociais, históricas, políticas e culturais, próprias da condição humana, passam a ser reduzidas estritamente a uma dimensão biológica e médica, com notáveis efeitos ideológicos.

Nesse sentido, como aponta Birman (2001), a própria ideologia farmacológica que permeia a psicopatologia é tributária de uma lógica comum de produção da subjetividade na atualidade, em que o objeto droga aparece com sedutor apelo, o que incide sobre outra psicopatologia emergente do mal-estar na atualidade, a toxicomania. Contudo, essa vinculação é particularmente perniciosa na produção da subjetividade dos indivíduos deprimidos, como atesta Tavares:

\begin{abstract}
Conforme a experiência profissional nos atesta, os pacientes diagnosticados como "depressivos" possuem em comum algumas particularidades no que diz respeito às tentativas de lidar com seu sofrimento no âmbito das assistências em saúde. Como podemos observar, existe uma forma padronizada de (ex)-sistência desses sujeitos a partir do momento em que Ihes atestam o diagnóstico de depressão, isso como consequência direta do também padronizado diagnóstico e tratamento que lhes sucede. O que nos chama a atenção é o fato de que alguns desses pacientes, uma vez diagnosticados como depressivos e (in)devidamente medicados, perdem grande capacidade de abertura para uma psicoterapia e, quando em algum momento nelas apostam, trazem em sua queixa uma evidente insatisfação com relação à "vida medicalizada". (2010, p. 136)
\end{abstract}

Isso se dá porque o indivíduo deprimido é capturável pelo discurso da psicopatologia não apenas pelo seu desamparo nas configurações sociais da pós- 
modernidade ou contemporaneidade, mas porque há algo no discurso da psicopatologia que faz um compromisso com sua condição de deprimido. Essa característica do indivíduo deprimido é uma posição de recusa de qualquer penetração na dimensão propriamente psíquica de seu sofrimento. Como foi visto, é um indivíduo a quem dói desejar. Seu refúgio está no corpo: no corpo que dorme, que se recusa a levantar, que não quer viver. Seu desejo é ver isso passar, mas nessa passagem há uma resistência muito grande de entrada nas fantasias que ordenam esse sofrimento. Decorre daí a formação de compromisso envolvida no medicamento: uma promessa de alívio da dor sem entrar na subjetividade. Não é à toa, portanto que a medicação anti-depressiva faz tanto sucesso e é tão procurada. Não se trata apenas de um uso indiscriminado da medicação ou de um erro de diagnóstico, mas, também, de uma configuração bastante peculiar nas relações entre sociedade, ciência e indivíduo.

Em suma, o que se observa na depressão, segundo Birman (2001), é um perigoso conluio na retirada do sujeito: as configurações da pós-modernidade, em sua cultura narcísica, trazem como resultado negativo a emergência de indivíduos deprimidos, que recusam a penetração na dimensão propriamente psíquica. Essa recusa, por sua vez, encontra respaldo na descrição psicopatológica que efetua uma retirada da etiologia subjetiva e vende a ilusão da felicidade fácil que, em contrapartida, retroalimenta o ideal da cultura performática. Tal condição subjetiva implica uma perpetuação do mal-estar por meio de um processo de desresponsabilização de si ou, como indica Tavares, de um "desejo de autoalienação" (2010, p. 151). Nesse sentido, caberia à psicanálise uma posição de desconstrução desse conluio, como apontam Machado e Ferreira

Nesse contexto, qualquer reflexão sobre si fica excluída ou se torna obsoleta, uma vez que remete ao sofrimento psíquico e à interioridade do sujeito. Esquece-se, por exemplo, que a psicanálise, acessando o inconsciente e tomando a depressão como um sintoma do sofrimento psíquico em suas diferentes roupagens na atualidade, é capaz de resgatar essa interioridade e acessar a verdade do sujeito através da fala. (2014, p. 136)

Vê-se, portanto, como uma perspectiva crítica pode dar um quadro compreensivo mais interessante para o problema da depressão no mal-estar da atualidade. Isso, contudo, não é suficiente para trabalhar a vertente psíquica desse mal-estar, apesar de que essa desconstrução por si só já seja bastante positiva. Lembra-nos que a depressão não é uma entidade flutuante, mais uma produção da subjetividade das pessoas. A perspectiva que se propõe é um alerta para esse apagamento do psíquico na ideologia que se constroi acerca dos quadros depressivos. Isso, talvez, seja o mais essencial e pertinente do que a psicanálise tenha a dizer sobre a depressão. 


\section{A PSICOPATOLOGIA PSICANALÍTICA}

Apesar de ter sido construída sobre os termos e categorias da psiquiatria clássica, tais como neurose, psicose e perversão, a psicopatologia psicanalítica possui um referencial teórico e metodológico distinto. Enquanto a psicopatologia psiquiátrica parte de um paradigma descritivo, que busca, como visto acima, organizar por meio da compilação dos sintomas em entidades sindrômicas e em categorias nosográficas, a psicanálise resgata a dimensão propriamente do sofrimento como mobilizador e expressão dos processos subjetivos. Nesse sentido, a psicanálise parte de uma abordagem mais propriamente compreensiva da condição patológica por meio de seu método clínico. Ela vem se articular à tradição mais ampla da psicopatologia compreensiva que na psiquiatria se opôs aos modelos organicistas e funcionalistas, buscando a dimensão de sentido inerente ao sofrimento, por meio de referenciais de inspiração humanística e existencial. Essa vertente confluiu, mais recentemente, na proposta de um paradigma alternativo e crítico à tradição psiquiátrica atualmente em voga, denominado de psicopatologia fundamental (Berlinck, 2008). Essa perspectiva está calcada no resgate da noção grega de páthos, entendida como uma condição passiva e passional por meio do qual se produz também o caminho de cura e em um resgate da clínica como um cuidado que se debruça sobre a singularidade e particularidade do sofrimento das pessoas.

Nesse contexto, a psicopatologia propriamente psicanalítica vem trazer como diferencial a diferenciação entre os planos sintomatológicos e estrutural. Isso quer dizer que os sintomas são pensados como produtos de certa configuração de mecanismos hipotéticos do aparelho psíquico. Essa estrutura, por sua vez, é descrita a partir dos mecanismos psicodinâmicos próprios do referencial, calcados na noção de desenvolvimento da personalidade ou de constituição do sujeito, a partir do quadro geral da teoria da libido e do complexo de Édipo. Além disso, entende-se que a estrutura subjetiva é apreensível a partir do método psicanalítico, por meio de sua escuta interpretativa e do vínculo transferencial (Leite, 2002; Dor, 1991; Bergeret et al., 2006; Vaisberg \& Machado, 1999). Quer seja na psicopatologia de inspiração lacaniana (Leite, 2002; Dor, 1991), em que a compreensão etiológica se dá a partir das três formas de resposta à castração instaurando lógicas distintas de organização da subjetividade, quer seja na psicopatologia inspirada na tradição das relações de objeto (Bergeret et al., 2006; Vaisberg \& Machado, 1999), em que os critérios metapsicológicos são definidos pela angústia organizadora e pelo modo de relação objetal predominante, a situação é pensada da mesma forma: o sintoma é produto da organização dinâmica da estrutura psicopatológica.

A depressão é uma configuração psicopatológica que traz questionamentos para a psicanálise por dois motivos. O primeiro é que a depressão, de fato, assumiu características patológicas mais marcadas nas últimas décadas, sendo 
uma das formas contemporâneas de adoecimento psíquico que estão fora dos quadros mais clássicos da psicopatologia psicanalítica. O outro fator é que, historicamente, o afeto depressivo ocupou um lugar marginal ao longo do desenvolvimento da teoria psicanalítica, a começar por seu fundador.

Depressão, dor e angústia dizem respeito à expressão afetiva da intensidade pulsional, não fazendo parte de uma caracterização psicopatológica específica. Contudo, diferentemente da angústia, que se tornou o afeto por excelência da investigação psicanalítica, o afeto depressivo não obteve o mesmo destaque (Delouya, 2001). É só no texto Luto e Melancolia, que Freud (1917/1996) dará um tratamento específico ao tema da depressão/melancolia. Nesse conhecido estudo, o autor irá desenvolver a hipótese de uma etiologia psicogênica para a melancolia, tomando-a em analogia com os processos de luto. De forma resumida, a hipótese é que pela impossibilidade do trabalho de luto normal a sombra do objeto recai sobre o ego por meio de uma identificação. Isso quer dizer que pela impossibilidade de desinvestimento do objeto perdido de amor, há uma inversão do afeto em seu oposto, que leva a uma transformação do amor objetal em ódio, e, além disso, há uma identificação do ego com o objeto perdido, levando o sadismo a se voltar contra o próprio sujeito, por meio de uma reflexão do investimento do objeto sobre o eu (Freud, 1917/1996). O ponto de fixação dessa problemática se dá justamente no momento de constituição do vínculo com o objeto, no momento do narcisismo.

Esse estudo é responsável pelo aprofundamento de uma linha mestra em psicanálise: a noção de que as identificações primárias junto ao objeto são o que antecedem e condicionam as relações objetais. Além disso, nele se indica o parentesco entre a melancolia e as psicoses, já que ambas serão referidas inicialmente à categoria das neuroses narcísicas, em oposição às neuroses de transferência. Nesse aspecto, é interessante notar que dentro da psicopatologia psicanalítica desenvolvida por Freud, como apontam Laplanche e Pontalis (1998), a melancolia permanecerá como a única das "neuroses narcísicas", diferenciada, por um lado das neuroses e, por outro, das psicoses. Isso nos indica que na melancolia a problemática narcísica é o eixo central da definição da psicopatologia. Além disso, com isso a melancolia será referida a um quadro psicopatológico específico, enquanto os sintomas depressivos podem se apresentar em diferentes configurações psicopatológicas. Desde então, classicamente, a psicanálise distingue entre uma psicopatologia específica, a melancolia, dos sintomas depressivos inespecíficos.

Será nesse percurso que a psicanálise das relações de objeto, com Klein (1935/1996, 1940/1996), irá desenvolver a problemática da elaboração da posição depressiva como um ponto nodal do desenvolvimento da personalidade. É na esteira da constituição do eu, em sua relação identificatória com a mãe, que se instaura a potencialidade melancólica. Essa condição se daria no momento constitutivo das relações de objeto totais, ocorrendo concomitantemente a do eu 
do sujeito. A melancolia eclode, segundo essa concepção, com o desenvolvimento da consciência de ser separado da mãe em seu distanciamento progressivo do primeiro objeto de identificação (Delouya, 2001). Esse caminho nos leva à afirmação de um eixo narcísico da melancolia, em que a problemática principal gira em torno de uma angústia pela perda do objeto de amor. A noção de uma problemática narcísica constitui o aspecto essencial da compreensão psicanalítica da depressão/melancolia (Campos, 2013; Green, 1988; Mendes, Viana, \& Bara, 2014). Essa idéia se mantém nas grandes linhagens pósfreudianas, apesar de algumas diferenças.

$\mathrm{Na}$ escola inglesa, a depressão está remetida diretamente ao conceito de posição depressiva em Melanie Klein (1935/1996, 1940/1996). A angústia depressiva é uma aquisição do desenvolvimento psíquico, em que o aparelho psíquico consegue integrar o bom e o mau objeto, operando um movimento de reparação do objeto danificado em fantasia, ou seja, a angústia depressiva surge do luto pelo dano ao objeto de amor, agora unificado em seus aspectos bons e maus. A posição depressiva se segue à elaboração da posição esquizo-paranoide (1946/1996), quando da integração do ego e dos objetos, por meio de uma elaboração das fantasias destrutivas em relação ao objeto materno. A posição depressiva envolve, nesse sentido, a angústia de perda de objeto e o mecanismo de reparação. Além disso, a elaboração falha das fantasias nessa posição se articula com um conjunto de defesas maníacas, caracterizadas por Segal (1975) como uma conjunção de sentimentos de controle, triunfo e desprezo pelo objeto na tentativa de negar a dependência do mesmo. Assim, se estabelece na perspectiva kleiniana mais claramente a relação intrínseca entre melancolia e mania. Além disso, o olhar kleiniano sobre a questão das depressões e melancolia acrescenta algumas nuances ao modelo freudiano inicial:

Se em Freud a tônica era dada à angústia de perda do objeto, com Klein essa perda do objeto está associada a uma fantasia primitiva de destruição do objeto, o que quer dizer que, inconscientemente, o sujeito não só se ressente do objeto que o abandonou, mais se culpa pela destruição do objeto de amor. Essas considerações trazem, portanto, uma compreensão renovada para a questão da autorecriminação melancólica descrita por Freud. (Campos, 2013, p. 18)

Essa compreensão da posição depressiva como uma aquisição positiva do desenvolvimento emocional marcou uma tradição dentro da psicanálise inglesa, sendo fundamental para os desenvolvimentos posteriores da teoria das relações de objeto, notadamente com Bion e Winnicott, que desenvolveram a idéia da contratransferência como uma função metabolizante das angústias do analisando (Souza \& Campos, 2014). Nessa esteira, a depressão originária é vista como uma função constituinte do aparelho psíquico, como expôs Fédida (1999). Tratase da ideia de que é a elaboração do afeto depressivo o fulcro da dinâmica de constituição do espaço psíquico, de forma tal que a depressividade é constitutiva da própria tópica e o sentido de identidade do eu (Delouya, 2001). O que seria 
da ordem da psicopatologia depressiva consiste em uma falha na elaboração dessa depressividade originária própria do narcisismo constitutivo, em uma forma de esvaziamento e desinvestimento mortífero e paralisante:

A depressão é, assim, um estado de vazio, de ausência, correspondendo a um tempo parado expondo o lugar e espaço, o fundo em relação ao qual ecoa o tempo da psique e permitindo dizer que ela define-se por uma posição econômica que concerne a uma organização narcísica do vazio segundo uma determinação própria para a inalterabilidade tópica da psique. (Berlinck \& Fédida, 2000, p. 15)

Essa falha na elaboração narcísica, contudo, pode se desdobrar em diferentes arranjos estruturais ao longo dos pólos neurótico e psicótico, de tal forma que o sintoma depressivo se apresentaria em diferentes configurações estruturais. É o caso da classificação proposta por Rocha (2008), que define os tipos neurótico, melancólico e borderline como expressões da problemática depressiva nas estruturas neurótica, psicótica e borderline, respectivamente. De qualquer forma, na tradição da psicanálise das relações de objeto, o afeto depressivo tende a ser valorizado na escola inglesa como expressão de uma dinâmica de elaboração psíquica e, nesse sentido, a depressão tende a ser vista como um momento positivo, uma abertura ao sofrimento e um movimento de tentativa de elaboração (Winnicott, 1999; Fédida, 1999).

Já na tradição lacaniana, a depressão está referida também a questão melancólica, mas compreendida em sua referência ao estágio do espelho e ao narcisismo, mais especificamente na queda da posição de objeto do desejo materno, via metáfora paterna (Dor, 1989). A problemática remete, portanto, ao ter de se haver com o desejo do Outro. A saída depressiva constitui, portanto, uma inibição do desejo próprio. Para utilizar uma ilustração, é como se o sujeito caísse em depressão para não desejar. O cair, aqui, é quase literal, como atesta a descrição dos sentimentos depressivos, ancoradas nos aspectos de prostração, retraimento, horizontalidade e negação do olhar do outro. A potencialidade depressiva é também referida a um momento da constituição do sujeito. Nesse sentido, define-se uma potencialidade depressiva própria da condição humana, advinda da própria dor de existir do sujeito alienando-se no império da linguagem. É isso que faz com que Lacan (1973/1993), em seu estilo jocoso, defina a depressão como uma covardia moral. Assim, nessa perspectiva, a depressão, não passaria de um sintoma o qual pode estar presente em diversas estruturas e, mais importante, seria caracterizado de forma negativa, pois seria expressão de um movimento de recusa ao desejo e à posição de sujeito. Desse modo, pode-se dizer que é um recurso de embotamento afetivo para evitar propriamente a angústia, esta sim, positiva (Dias, 2003). Outra coisa é a melancolia, que seria uma saída específica na estruturação da subjetividade a partir dessa potencialidade depressiva originária. Nela, a saída se dá por um mecanismo específico, a foraclusão do nome-do-pai, o que coloca a melancolia 
no campo da estrutura psicótica (Quinet, 2006). A diferença principal é que na psicose não haveria a marca da identificação fálica, enquanto na depressão sim, como esclarece Kehl:

No caso do depressivo, a identificação fálica ocorreu. O depressivo está marcado por ela, pela experiência de ter representado, para sua mãe, o falo. Também está marcado pela queda desse lugar privilegiado: o depressivo não é um psicótico. A dor moral de que sofre é de natureza diferente da do melancólico. O depressivo está marcado pela castração, mas não a simboliza - até aqui, não se diferencia do neurótico. Só que a castração é para ele motivo de dor narcísica e também de vergonha (são estes os componentes de sua dor moral), uma vez que ele se instalou na condição de castrado por covardia - para esquivar-se da rivalidade fálica com o pai e, consequentemente, com os substitutos dele, ao longo da vida. Permanece, portanto, na versão imaginária da castração infantil: aquele que nada pode. Se tivesse entrado na rivalidade com o pai, como faz o neurótico, o depressivo estaria fadado à derrota; mas, como ele preferiu se retirar do jogo sem nem ao menos tentar, o depressivo se envergonha de sua impotência. (2009, p. 201)

Entende-se assim, na tradição lacaniana a melancolia como uma substrutura psicótica, já o que é referido como depressão é da ordem de um sintoma afetivo inespecífico, ligado a uma posição diante da assunção do desejo mais próximo da neurose, mas que pode estar presente em diferentes arranjos estruturais (Peres, 2003).

Contudo, essa perspectiva estrutural sobre a melancolia e sobre a depressão diz respeito à teoria lacaniana clássica, calcada no campo do significante e na articulação simbólico-imaginária, em que a subjetividade é entendida em termos de saídas estruturantes à castração simbólica. Além disso, a teoria lacaniana avançou, em seu último momento, para o campo do gozo, em que se ressalta o registro do Real, com destaque para marcas anteriores ao campo da linguagem e articuladas à negatividade do objeto a (Kaufmann, 1996; Dor, 1989). Nessa perspectiva do último Lacan, o regime da subjetividade está relacionado fundamentalmente à dimensão do desamparo originário e do objeto a, entendendo-se que a negatividade própria do Real e a insistência da compulsão à repetição própria da pulsão em sua dimensão mais fundamental impõem-se como uma ruptura ao saber estruturado no campo do simbólico. Nesse sentido, o registro do Real comparece como uma negatividade criativa e produtora de diferença em relação ao instituído e estruturado no plano da linguagem. Nesse sentido, a pulsão de morte aparece assim como uma dimensão de irrupção da diferença e da criatividade (Garcia-Roza, 1990). A pulsão assim entendida atua na reordenação das estruturas sedimentadas da subjetividade e toda a compreensão da subjetividade como uma estrutura sedimentada em função de uma lógica de simbolização é relativizada para se pensar uma visão mais fluída, pautada pela construção de laços sociais por meio de estruturas discursivas e pela amarração singular dos registros subjetivos na forma do 
sinthoma (Quinet, 2008). Por fim, nesse ponto do percurso de Lacan (1960/1988), destaca-se uma inflexão para uma perspectiva propriamente ética como fundamento da subjetividade, em que o destaque é dado para as condições de produção de uma posição de sujeito, entendido como a assunção de sua condição de desejante e sua abertura para a alteridade radical que o habita.

Nesse contexto, os afetos depressivos comparecem de forma paradigmática, uma vez que sua negatividade, em termos de sentimento de vazio, de embotamento afetivo e de inibição da ação, estão diretamente ligados a destinos libidinais em que a pulsão de morte é preponderante. Contudo para além de uma mera visão negativa sobre o fenômeno, a partir desse quadro ampliado é possível pensar também que os estados depressivos são posições privilegiadas de contato com essa potencialidade criativa que é a pulsão em sua dimensão originária, daí a possibilidade de pensa-los como oportunidades de resgate da condição de sujeito desejante. De todo modo, a depressão aparece como uma figura privilegiada para pensar a relação entre o mal-estar e uma ética do desejo pensada, sobretudo, como uma forma de resistência. É a partir desses últimos aportes que se tem, a partir de uma perspectiva contemporânea em psicanálise, se insistido no lugar paradigmático que as depressões ocupam na contemporaneidade. É também por esse caminho que a reflexão psicopatológica reencontra a crítica social, como pode ser atestado na seguinte passagem:

Finalmente, é de uma questão ética que se propõe a psicanálise ao lançar resistência ante os modos priorizados pela sociedade capitalista e espetacular. Uma ética que priorize uma estilística de existência às avessas do que nos circunda atualmente, que reconheça a dimensão singular das individualidades com tudo o que isso comporta de vislumbre sobre o conflito sempre humano, demasiadamente humano, e que possa desfrutar das possibilidades que nos abrem ao nos desvelarmos de toda a alienação. (Tavares \& Hashimoto, 2010, p. 98)

De todo modo, é possível notar ao longo desse percurso pelas tradições em psicanálise certa convergência em relação a compreensão da problemática depressiva. Apesar de algumas tônicas gerais poderem ser percebidas no tratamento do tema pelas vertentes majoritárias do campo, em especial em suas posições mais clássicas, tais como a ênfase na dimensão de inibição e recuo ou na potencialidade criativa, o fato é que o encaminhamento da teorização acaba por contemplar esse espectro de elementos e, principalmente, acaba por apontar para uma relação muito especial entre a problemática depressiva e a constituição da subjetividade e do desejo. Não obstante, essas diferenças na concepção teórica implicam divergência na técnica de trabalho com os pacientes depressivos, as quais não cabem ao escopo deste artigo. De todo modo, cabe apontar que ambas as perspectivas, de formas distintas, convergem para certo ponto paradigmático comum que é a problemática narcísica na constituição da subjetividade. É nesse sentido que na psicanálise contemporânea essas meadas 
teóricas oriundas de diversas tradições têm sido resgatadas e alinhavadas de forma bastante original.

Um autor que se destacou em retomar essas duas tradições pósfreudianas para resgatar a centralidade da dimensão narcísica na problemática depressiva é André Green. Em vários trabalhos, a começar por um seminal estudo sobre o narcisismo (Green, 1988) e depois sobre o trabalho do negativo (Green, 2010), o autor defende que se retome a problemática do negativo na dinâmica narcísica, ressaltando os movimentos de desinvestimento e desobjetalização próprios das pulsões de morte na constituição de um narcisismo reativo e negativo, marcado por angústias de esvaziamento e mortificação. Essa dinâmica de neutralização e nadificação teria como expressão emblemática vários sintomas do espectro das depressões. Por esse caminho o autor propõe a caracterização de um eixo narcísico-melancólico na constituição da subjetividade como perspectiva privilegiada na compreensão da configuração das organizações limítrofes de personalidade e de outros arranjos característicos das psicopatologias contemporâneas. Portanto, a despeito das diferentes nuances, é possível encontrar na literatura propostas de sistematização mais abrangentes. Do mesmo modo, pode se defender que, endossando Mendes et al. (2014, p. 429): "o modelo narcísico-melancólico, desenvolvido por Green, se mostra mais adequado para a compreensão das patologias contemporâneas". Nesse sentido, o aprofundamento da teorização sobre o eixo narcísico-melancólico do desenvolvimento da personalidade consiste uma contribuição importante e relevante para a compreensão do espectro das psicopatologias na atualidade.

\section{CONSIDERAÇÕES FINAIS}

Com isso encerra-se a apresentação dos argumentos em função de uma crítica psicanalítica à compreensão psiquiátrica corrente sobre as depressões, que sustenta a visão do senso comum sobre essa psicopatologia, alçada à condição de sintoma emblemático do sofrimento na contemporaneidade. Este artigo procurou mostrar que esse fenômeno se enraíza profundamente como expressão em negativo de um contexto sócio-cultural específico pautado por um ideal performático de subjetivação. Nesse sentido, uma perspectiva psicanalítica serve a uma posição de resistência às tendências contemporâneas de dessubjetivação e reificação próprias dos movimentos de medicalização e biologização do social.

Além disso, buscou mostrar como uma escuta psicanalítica dos sintomas depressivos está centrada na problemática narcísica de constituição da subjetividade, tendo variações em sua compreensão dentro da psicopatologia psicanalítica, mas nunca configurando uma estrutura específica, estando presente em diversas configurações estruturais. Desse modo, as depressões são mais um sintoma a ser interpretado no quadro geral da estrutura subjetiva do 
que propriamente um rótulo ou categoria psicopatológica. Por fim, há também, no campo psicanalítico, diferenças quanto à compreensão essencial dos estados depressivos e seu manejo clínico, mas apesar disso, pode-se notar também certa convergência em sua dimensão fundamental, com importantes implicações éticas que apontam para o seu lugar de destaque na atualidade.

De qualquer forma, a relevância, pertinência e prevalência de preocupações com relação às depressões a partir da psicanálise se justificam e só pode ser compreendida a partir do quadro de referência mais amplo do contexto sócio-cultural de produção da subjetividade na atualidade. Nesse sentido, a psicanálise pôde mais recentemente trazer importantes aportes teórico-conceituais na compreensão da dinâmica dessa psicopatologia e também alçando sua problemática a um lugar central para a compreensão do campo mais geral das psicopatologias contemporâneas. Com isso também, ela pôde construir importante crítica ao discurso hegemônico atual sobre a saúde mental, marcado pela desresponsabilização subjetiva. Assim, este percurso demonstra a pertinência da problemática das depressões como ilustração da expressão da problemática narcísica como eixo norteador para as subjetividades contemporâneas, tanto em sua dimensão teórico-clínica quanto sociocultural.

\section{REFERÊNCIAS}

Associação Psiquiátrica Americana. (2002). DSM-IV: manual diagnóstico e estatístico de transtornos mentais. 4. ed. Porto Alegre, RS: Artmed.

Associação Psiquiátrica Americana. (2014). DSM-5: manual diagnóstico e estatístico de transtornos mentais. 5. ed. Porto Alegre, RS: Artmed.

Bauman, Z. (1998). O mal-estar da pós-modernidade. Rio de Janeiro, RJ: Jorge Zahar.

Bergeret. J., Bécache, A., Boulanger, J.-J., Chartier, J.-P., Dubor, P., Houser, M., \& Lustin, J.-J. (2006). Psicopatologia: teoria e clínica. 9. ed. Porto Alegre, RS: Artmed.

Berlinck, M. T. (2008). Psicopatologia fundamental. São Paulo, SP: Escuta.

Berlinck, M. T., \& Fédida, P. (2000). A clínica da depressão: questões atuais. Revista Latinoamericana de Psicopatologia Fundamental, 3(2), 9-25.

Birman, J. (2001) Mal-estar na atualidade: a psicanálise e as novas formas de subjetivação. 2. Ed. Rio de Janeiro, RJ: Civilização Brasileira.

Birman, J. (1991). A constituição da clínica psicanalítica. In J. Birman, Freud e a interpretação psicanalítica (pp. 135-166). Rio de Janeiro, RJ: RelumeDumará.

Birman, J. (2006). A psicanálise e a crítica da modernidade. In J. Birman, Arquivos do mal-estar e da resistência (pp. 33-56). Rio de Janeiro, RJ: Civilização Brasileira. 
Bogochovol, A. (2001). Sobre a psicofarmacologia. In: M. C. R. Magalhães (Org.), Psicofarmacologia e psicanálise (pp. 35-62). São Paulo, SP: Escuta.

Caponi, S. (2009). Uma análise epistemológica do diagnóstico de depressão. Intreface (Botucatu), 13(29), 327-338. doi: 10.1590/S141432832009000200007

Campos, E. B. V. (2013). Considerações sobre a morte e o luto em psicanálise. Psicologia UNESP, 12(1), 13-24.

Conrad, P. (2007). The medicalization of society: on the transformation of human conditions into treatable disorders. Baltimore: The Johns Hopkins University Press.

Dalgalarrondo, P. (2000). Psicopatologia e semiologia dos transtornos mentais. Porto Alegre, RS: Artmed.

Debord, G. (1997). A sociedade do espetáculo. Rio de Janeiro, RJ: Contraponto.

Dias, M. M. (2003). A posição do sujeito na depressão: uma abordagem psicanalítica. Caderno do seminário: neuroses e depressão. Campinas, SP: Instituto de Psiquiatria de Campinas.

Dor, J. (1991). Estruturas e clínica psicanalítica. Rio de Janeiro, RJ: TaurusTimbre.

Dor, J. (1989). Introdução à leitura de Lacan: o inconsciente estruturado como linguagem. Porto Alegre, RS: Artes Médicas.

Delouya, D. (2001). Depressão. 2. Ed. São Paulo, RJ: Casa do Psicólogo.

Freud, S. (1996). Introdução ao narcisismo. In S. Freud, Edição standard brasileira das obras completas de Sigmund Freud, v. XIV (pp. 75-110). Rio de Janeiro, RJ: Imago. (Trabalho original publicado em 1914)

Freud, S. (1996). Luto e melancolia. In S. Freud, Edição standard brasileira das obras completas de Sigmund Freud, v. XIV (pp. 243-266). Rio de Janeiro, RJ: Imago. (Trabalho original publicado em 1917)

Freud, S. (1996). Psicologia das massas e análise do ego. In S. Freud, Edição standard brasileira das obras psicológicas completas de Sigmund Freud, v. XVIII (pp. 77-154). Rio de Janeiro, RJ: Imago. (Trabalho original publicado em 1921)

Fédida, P. (1999). Depressão. São Paulo, SP: Escuta.

Foucault, M. (1978). História da loucura. São Paulo, SP: Perspectiva.

Foucault, M. (1998). O nascimento da clínica. Rio de Janeiro, RJ: Forense Universitária.

Foucault, M. (2008). Nascimento da biopolítica. São Paulo, SP: Martins Fontes.

Garcia-Roza, L. A. (1990). O mal radical em Freud. Rio de Janeiro, RJ: Jorge Zahar.

Gorayeb, R. (2002). Subjetividade ou objetivação do sujeito? In M. L. V. Violante (Org.), O (im)possível diálogo psicanálise e psiquiatria (pp. 139-164). São Paulo, SP: Via Lettera. 
Green, A. (1988). Narcisismo de vida: narcisismo de morte. São Paulo, SP: Escuta.

Green, A. (2010). O trabalho do negativo. Porto Alegre, RS: Artmed.

Ilich, I. (1975). A expropriação da saúde: nêmesis da medicina. Rio de Janeiro, $\mathrm{RJ}$ : Nova Fronteira.

Kaufmann, P. (1996). Dicionário enciclopédico da psicanálise: o legado de Freud a Lacan. São Paulo, SP: Martins Fontes.

Kehl, M. R. (2009). O tempo e o cão: a atualidade das depressões. São Paulo, SP: Boitempo.

Klein, M. (1996). Uma contribuição à psicogênese dos estados maníacodepressivos. In M. Klein, Amor, culpa e reparação e outros trabalhos (pp. 301-329). Rio de Janeiro, RJ: Imago. (Trabalho original publicado em 1935)

Klein, M. (1996). O luto e suas relações com os estados maníaco-depressivos. In: M. Klein, Amor, culpa e reparação e outros trabalhos (pp. 385-412). Rio de Janeiro, RJ: Imago. (Trabalho original publicado em 1940)

Klein, M. (1996). Notas sobre alguns mecanismos esquizóides. In M. Klein, Inveja e gratidão e outros trabalhos ( $\mathrm{pp} .17-43$ ). Rio de Janeiro, RJ: Imago. (Trabalho original publicado em 1946)

Kramer, P. D. (1994). Ouvindo o prozac: uma abordagem profunda e esclarecedora sobre a pílula da felicidade. Rio de Janeiro, RJ: Record.

Lacan, J. (1998). O estádio do espelho como formador da função do eu tal como nos revela a experiência psicanalítica. In J. Lacan, Escritos (pp. 96-103). Rio de Janeiro, RJ: Jorge Zahar. (Trabalho original publicado em 1949)

Lacan, J. (1993). Televisão. Rio de Janeiro, RJ: Jorge Zahar. (Trabalho original publicado em 1973)

Lacan, J. (1988). O seminário: livro 7 - A ética da psicanálise. Rio de Janeiro, RJ: Jorge Zahar. (Trabalho original escrito em 1960)

Laplanche, J., \& Pontalis, J.-B. (1998). Vocabulário da psicanálise. 4. ed. São Paulo, SP: Martins Fontes.

Lasch, C. (1983). A cultura do narcisismo: a vida americana numa era de esperanças em declínio. Rio de Janeiro, RJ: Imago.

Leite, M. P. de S. (2002). Psiquiatria, sujeito e psicanálise. In M. L. V. Violante (Org.), O (im)possível diálogo psicanálise e psiquiatria (pp. 101-127). São Paulo, SP: Via Lettera.

Machado, L. V., \& Ferreira, R. R. (2014). A indústria farmacêutica e a psicanálise diante da "epidemia de depressão": respostas possíveis. Psicologia em Estudo, 19(1), 135-144. doi: 10.1590/1413-7372219160013

Mendes, E. D., Viana, T. C., \& Bara, O. (2014). Melancolia e depressão: um estudo psicanalítico. Psicologia: Teoria e Pesquisa, 30(4), 423-431.

Nogueira Filho, D. M. (2001). Sobre a psiquiatria e a psicanálise. In M. C. R. Magalhães (Org.), Psicofarmacologia e psicanálise (pp. 23-34). São Paulo, SP: Escuta. 
Organização Mundial de Saúde (2001). Relatório sobre a saúde no mundo 2001: saúde mental: nova concepção nova esperança. Genebra: OMS.

Organização Mundial de Saúde (1993). Classificação dos transtornos mentais e de comportamento da CID-10. Porto Alegre, RS: Artes Médicas.

Peres, U. T. (2003). Depressão e melancolia. Rio de Janeiro, RJ: Jorge Zahar.

Pignarre, P. (2012). Comment la dépression est devenue une épidémie. Paris: La Découverte.

Quinet, A. (2006). Teoria e clínica da psicose. São Paulo, SP: Forense Universitária.

Quinet, A. (2008). Psicose e laço social: esquizofrenia, paranoia e melancolia. Rio de Janeiro, RJ: Jorge Zahar.

Rocha, Z. (2008). Para uma abordagem estrutural da depressão: contribuições freudianas. Psychê, 12(23). Recuperado de http://pepsic.bvsalud.org/scielo.php?script=sci_arttext\&pid=S1415$11382008000200001 \&$ Ing $=$ pt\&tlng=pt.

Rodrigues, M. J. S. F. (1999). O diagnóstico de depressão. Psicologia USP, 11(1), 155-157. doi: 10.1590/S0103-65642000000100010

Segal, H. (1975). Introdução à obra de Melanie Klein. Rio de Janeiro, RJ: Imago.

Souza, J. G. E., \& Campos, É.B.V. (2014). A contratransferência e a importância das capacidades do analista na prática psicanalítica contemporânea. Impulso: Revista de Ciências Sociais e Humanas, 24, 123-132.

Tavares, L. A. T. (2010). A depressão como "mal-estar" contemporâneo: medicalização e (ex)-sistência do sujeito depressivo. São Paulo, SP: Cultura Acadêmica.

Tavares, L. A. T., \& Hashimoto, F. (2010). A relativa legitimidade da depressão na atualidade: contribuições para uma ética psicanalítica do sujeito. Latin American Journal of Fundamental Psychopathology, 7(1), 88-100.

Vaisberg, T. M. J. A., \& Machado, M. C. L. M. (1999). Diagnóstico estrutural de personalidade em psicopatologia psicanalítica. Psicologia USP, 11(1), 29-48. doi: $10.1590 /$ S0103-65642000000100003

Wakefield, J. C., \& Horwitz, A. V. (2010). A tristeza perdida: como a psiquiatria transformou a depressão em moda. São Paulo, SP: Summus Editorial.

Winnicott, D. W. (1999). Tudo começa em casa. 3. ed. São Paulo, SP: Martins Fontes. 
Sobre o autor

Érico Bruno Viana Campos é psicólogo, mestre e doutor em psicologia pelo Instituto de Psicologia da Universidade de São Paulo. É professor assistente doutor do departamento de psicologia da Faculdade de Ciências de Bauru da UNESP. Trabalha na linha de pesquisa "Psicanálise: Clínica, Teoria e Cultura" e recebe financiamento de pesquisa do CNPq. ebcampos@fc.unesp.br

Recebido em: 10/03/2016

Revisado em: 08/06/2016

Aceito em: 25/07/2016 